\title{
STRUCTURE AND PROPERTIES OF RAILWAY WHEEL SURFACE AFTER RESTORATION SURFACING AND SERVICE LOADING
}

\author{
L.I. MARKASHOVA, V.D. POZNYAKOV, A.A. GAJVORONSKY, \\ E.N. BERDNIKOVA and T.A. ALEKSEENKO \\ E.O. Paton Electric Welding Institute, NASU
}

11 Bozhenko Str., 03680, Kiev, Ukraine. E-mail: office@paton.kiev.ua

\begin{abstract}
Presented are the investigations of effect of composition of surfacing consumables on structure and phase composition of deposited metal of surfacing zones (surface, fusion line, HAZ) in restoration of railway wheels from grade 2 steel. Information received at different structural layers (from grain to dislocation) was used for analytical estimations of effect of parameters of forming structures on mechanical properties $\left(\sigma_{0.2}, K_{1 c}\right)$ of railway wheels, reconstructed by surfacing, before and after operation. Role of structural factors in change of level of local internal stresses $\tau_{\text {l.in }}$, i.e. sources of crack formation in subsurface layers of deposited metal, was investigated. It is determined that surfacing consumables of bainite and bainitemartensite classes provide for high indices of mechanical properties and crack resistance of railway wheels after restoration repair and operation. 9 Ref., 1 Table, 5 Figures.
\end{abstract}

$\boldsymbol{K} \boldsymbol{e} \boldsymbol{y} \boldsymbol{w} \boldsymbol{o} \boldsymbol{r} \boldsymbol{s}:$ surfacing, railway wheels, deposited metal, heat-affected zone, structure, phase composition, mechanical properties, crack resistance

Today problem of increase of service reliability and life of machines, mechanisms, parts etc. becomes more and more relevant. This problem is particularly critical for separate heavy loaded basic parts and mechanisms of running gear of cars and engines, main element of which is a wheel having direct contact with rail. Surface of wheel flange is subjected to the most significant wear in process of operation. Regardless different technological developments of restoration repair, problem of strength, reduction of wear level and crack resistance of railway wheels [1-3] is still relevant.

In relation to restoration surfacing of surface of wheel flange, the authors carried out preliminary examinations of structural-phase changes in metal close to the roll surface of railway wheels [4]. Role of each of structural factors (phase constituents, grain, subgrain and dislocation structures, phase precipitates etc.) in change of strength and crack resistance of metal of railway wheels was investigated based on obtained results. The results of experimental investigations, received at different structural levels, i.e. from macro (grain) to micro (dislocation), made a basis for performance of analytical estimation of specific (differential) input of separate structural-phase factors and parameters in change of general (integral) value of mechanical charac- teristics, namely strength $\sigma_{0.2}$, crack resistance $K_{1 c}$ as well as local internal stresses $\tau_{\text {l.in }}$ being a potential source of nucleation and propagation of cracks in investigated structural microareas [4-7].

As a result after operation of railway wheels, dispersed structures (ferrite-carbide mixture), band structures with their reorientation along metal depth (Figure 1, $a$ ) and rolled nonmetallic inclusions (NMI) (Figure 1, b) was formed in metal close to the roll surface (zones $1 \mathrm{R}-4 \mathrm{R}$, Figure $1, d$ ), in particular in 3R zone (transfer from roll area to wheel flange). Increased dislocation density (up to $(3-4) \cdot 10^{11} \mathrm{~cm}^{-2}$ ) is observed along the boundaries of these structural elements in zones of reorientation bands at the boundaries of cementite/ferrite $(\mathrm{C} / \mathrm{F})$ connection in pearlite constituent as well as in zones of «rolling» of NMI. This results in rise of local internal stresses along the boundaries of these structural elements up to $\tau_{1 . \text { in }} \sim 5200-7000 \mathrm{MPa}$ (makes $\left.(0.67-0.90) \tau_{\text {theor }}\right)$, which are potential sources of crack formation (Figure 1,c).

It was shown that the most significant structural changes in metal take place in transient zone from roll surface to flange with maximum change by depth to $200-300 \mu \mathrm{m}$, which result in significant strengthening (1.7-2.3 times) of subsurface layers and reduction of fracture toughness level (by $50 \%$ ) and noticeable increase (3-4 times) of local internal stresses in comparison 

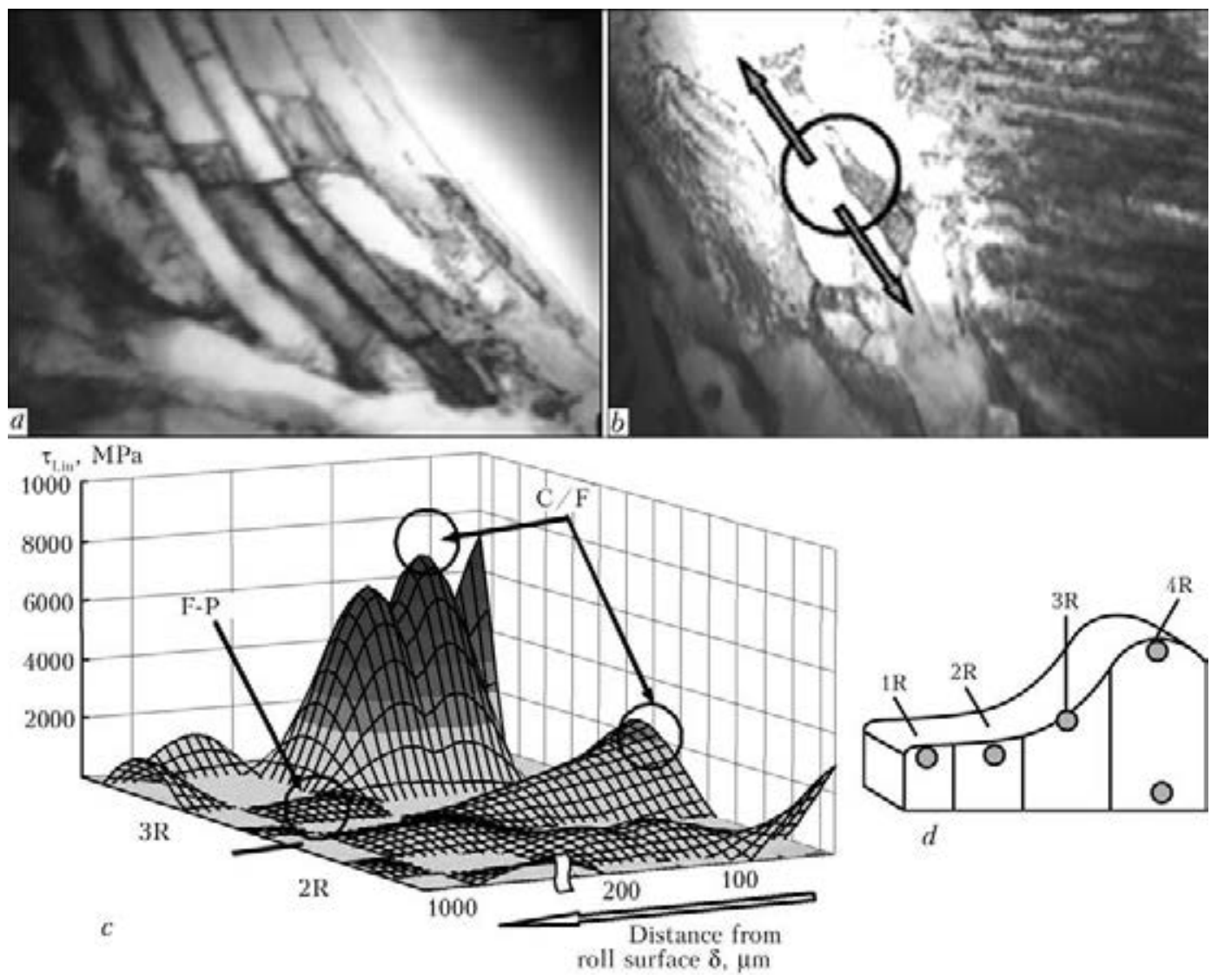

Figure 1. Fine structure $(a, b-\times 30000)$ of metal of roll zone, and local internal stresses $\tau_{\text {l.in }}(c)$ forming in subsurface layers at $\delta=0-200 \mu \mathrm{m}$ in metal of wheels in zones of roll surface $2 \mathrm{R}$ and 3R $(d)$ and their changes in moving from roll surface

with initial metal. This is explained by presence of microcracks in metal of subsurface layers. Increase of reliability of the wheel subjected to surfacing restoration requires preliminary removal of subsurface layer of metal in the place of planned surfacing in order to eliminate formation of subsurface cracks.

Next investigations of reasons of railway wheel fracture were carried out after their restoration surfacing depending on composition of welding wires, providing production of welds with ferrite-pearlite (F-P) and bainite-martensite (B-M) structures [8, 9]. Surfacing was carried out by mechanized method in $\mathrm{CO}_{2}$ using Sv-08G2S (F-P weld) and PP-AN180MN (B-M weld) wires. Chemical composition of produced weld metal is given in the Table.

Comparison of structural changes and phase composition of deposited metal and HAZ from point of view of effect on indices of strength, plasticity and crack resistance showed the following. Using PP-AN180MN wire promotes for formation of the most optimum B-M structure, which provides for absence of rapid gradients on size of structural constituents and microhardness, uniform phase composition and noticeable refin- ing of structure of deposited metal (in comparison to F-P weld).

The results of calculation estimations of fracture toughness $K_{1 c}$ for F-P and B-M welds as well as analysis of combination of $K_{1 c}$ and strength properties $\sigma_{\mathrm{y}}$ showed the following. Value of $K_{1 c}$ is somewhat higher (on average by $20 \%$ ) in surfacing using PP-AN180MN (B-M weld), that is promoted by formation of $\mathrm{M}-\mathrm{B}$ structure, refinement of grain, formation of substructure and uniform distribution of dislocations (Figure 2, b). High level of strength (Figure 2, a) is also observed at that. This indicates good combination of strength and plasticity characteristics of the deposited metal. Low $K_{1 c}$ index is typical for F-P weld, that is related with formation of gradient on sizes of grain structure and coarse grain pearlite constituent (Figure 2,c).

Aim of further investigations lied in examination of structure and mechanical properties of railway wheels, being repaired by restoration surfacing after operation, as well as analysis of effect of structural factors on their mechanical properties and crack resistance.

The work was carried out on welded joints of wheel steel 2 with, wt.\%: $0.55-0.65 \mathrm{C}$; $0.5-$ $0.9 \mathrm{Mn} ; 0.22-0.45 \mathrm{Si} ; \leq 0.1 \mathrm{~V}$, not more than 
Chemical composition of weld metal, wt.\%

\begin{tabular}{||l|c|c|c|c|c|c|c||}
\hline \multicolumn{1}{|c|}{ Wire grade } & $\mathrm{C}$ & $\mathrm{Mn}$ & $\mathrm{Si}$ & $\mathrm{Cr}$ & $\mathrm{Ni}$ & $\mathrm{V}$ & Mo \\
\hline Sv-08G2S & 0.10 & 2.10 & 0.95 & - & - & - & - \\
\hline Sv-08KhM & 0.12 & 1.36 & 0.60 & 0.60 & - & - & 0.42 \\
\hline Sv-08KhMF & 0.12 & 1.25 & 0.62 & 0.61 & - & 0.10 & 0.36 \\
\hline PP-AN180MN & 0.12 & 1 & 0.35 & 0.67 & 0.80 & 0.10 & 0.40 \\
\hline
\end{tabular}

$0.03 \mathrm{P}$ and $0.035 \mathrm{~S}$ (GOST 10791-89). Welding wires Sv-08KhMF, SV-08KhM (bainite-ferrite class) and PP-AN180MN (bainite-martensite class) were used as surfacing consumables (see the Table).

Structural-phase, concentration changes, nature of distribution and density of defects of crys-
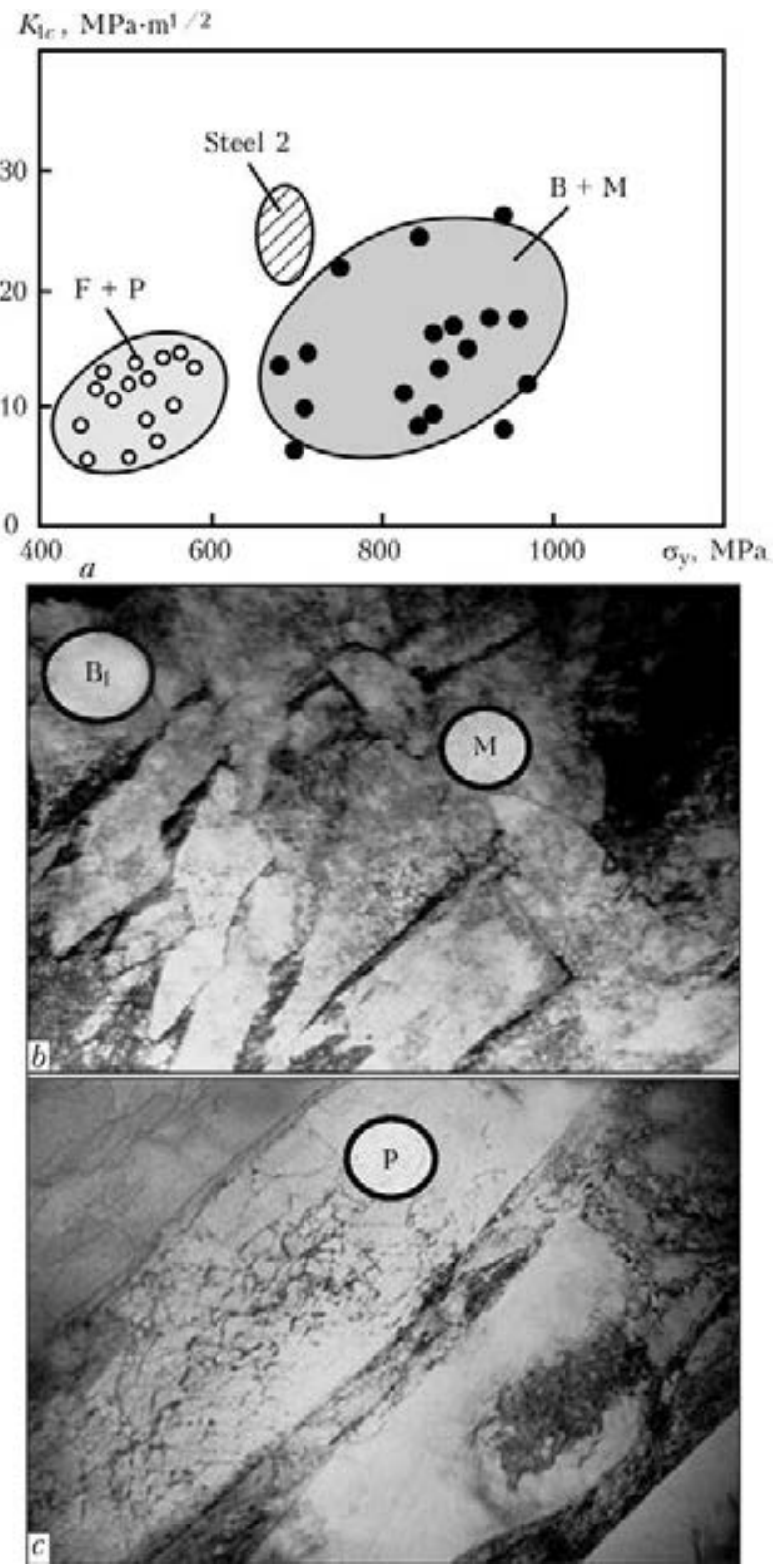

Figure 2. Comparison $(a)$ of calculation indices of mechanical properties of deposited metal and corresponding finegrain structure $(b)$ of lower bainite and martensite, and coarse-grain pearlite constituent $(c-\times 20000)$ talline lattice in different zones of welded joints were studied using complex of methods, including optical metallography, Philips analytical scanning electron microscopy SEM-515 and JEOL transmission electron microscopy JEM200CX.

The following was determined as a result of examination of NMI structure, their size and distribution, phase constituents (ferrite $\mathrm{F}$, pearlite $\mathrm{P}$, upper $\mathrm{B}_{\mathrm{u}}$ and lower $\mathrm{B}_{1}$ bainite), their volume fraction $\mathrm{V}, \%$, grain size $D_{\mathrm{g}}$ as well as changes of microhardness $H \mathrm{~V}$ along the zones of welded joint, namely deposited metal, fusion line (FL) and HAZ at depth $\delta$ from external surface of wear.

Using Sv-08KhMF and Sv-08KhM produce deposited metal having typical B-F structure; preferably silicate NMI with $d_{\mathrm{nmi}} \sim 15-20 \mu \mathrm{m}$ (separate) and dispersed $\left(d_{\mathrm{nmi}} \leq 2 \mu \mathrm{m}\right)$ with volume fraction up to $20 \%$ are formed. In the case of Sv-08KhM, 1.5 times increase of volume fraction of dispersed NMI in comparison to $\mathrm{Sv}^{-}$ $08 \mathrm{KhMF}$ is observed at $\delta \sim 0-50 \mu \mathrm{m}$. Using PPAN-180MN provides for formation of M-B structure along depth of the deposited metal at reduction of crystalline size approximately in 1.4 times, increase of $H V$ around by $5-15 \%$ in comparison to B-F welds in presence of mainly dispersed NMI with $d_{\mathrm{nmi}} \leq 1 \mu \mathrm{m}$.

The following can be observed for all investigated types of deposited metal, i.e. dispersion of structure at increase of its microhardness per 10-25 \% (in F-P welds) and per 5-10 \% (in B-M weld), formation of elongated bands of deformation with $\kappa \sim 5-12$ (F-P welds) and $\kappa \sim 6-8$ (B-F welds) oriented at $\sim 20-30^{\circ}$ angle relatively to external surface.

It is determined that the most optimum structure of deposited metal (from point of view of uniform increase of microhardness, refinement of structure, dispersion of NMI and their uniform distribution) is formed in the case of PPAN180MN application. Metal of such welds is characterized by absence of rapid gradients in microhardness as well as size of structural constituents. Microhardness of structural constituents at its uniform increase in further HAZ areas rises by $12 \%$ at transfer into wheel steel in coarsegrain area. Such structural changes, obviously, should provide for uniform increase of strength properties in railway wheels repaired using surfacing.

Methods of scanning electron microscopy were applied for examination of peculiarities of change of fine structure (width of laths, size of substructure, nature of dislocation structure). Band struc- 

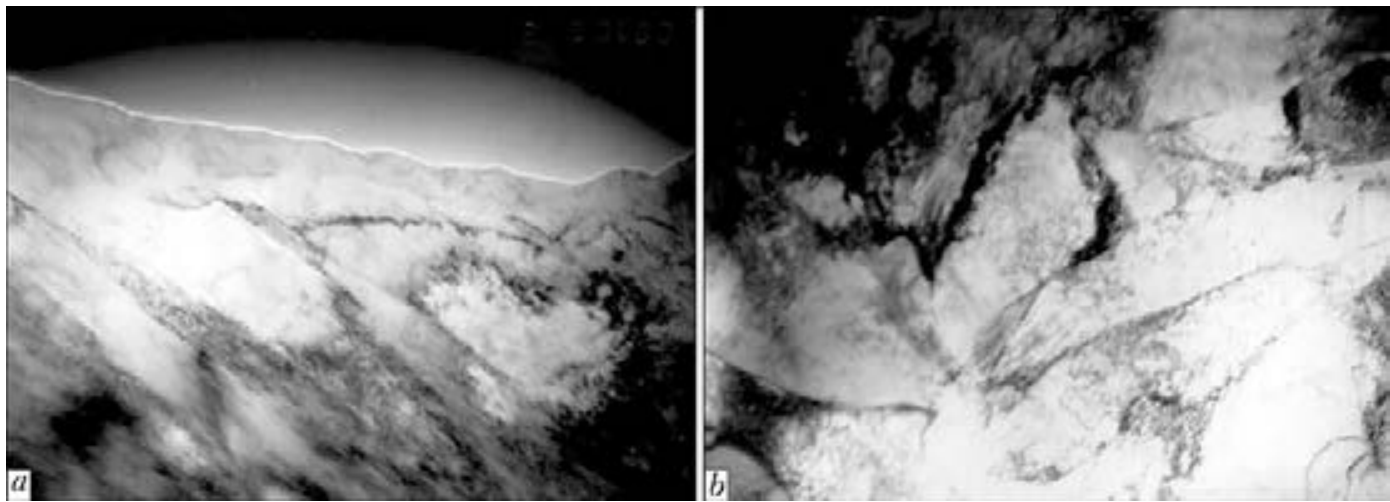

Figure 3. Fine structure $(\times 30000)$ of deposited metal near wear surface in surfacing using PP-AN180MN wire: $a-$ band structures; $b-$ lower bainite fragmentation at $\delta \sim 200 \mu \mathrm{m}$

tures are formed (Figure 3, a) at $\delta \sim 0-100 \mu \mathrm{m}$ distance (PP-AN180MN) from external surface after service loading. Structure fragmentation is also observed, i.e. width of deformation bands of $\sim 0.15-0.5 \mu \mathrm{m}$, size of fragments (or substructure) $d_{\mathrm{s}} \sim 0.3-0.5 \mu \mathrm{m}$ at increase of dislocation density up to $\rho \sim(1-2) \cdot 10^{11} \mathrm{~cm}^{-2}$ (Figure $3, b$ ). Fragmented structure of lower bainite with width of bainite lath of $\sim 0.2-0.6 \mu \mathrm{m}$ is formed at transfer to FL (at $\delta \sim 0-200 \mu \mathrm{m}$ from it). Size of subgrains of ferrite constituent is around $d_{\mathrm{s}}$ $\sim 0.5-1 \mu \mathrm{m}$. Dislocation density in weld metal makes $\rho \sim(4-6) \cdot 10^{10} \mathrm{~cm}^{-2}$.

HAZ metal at transfer into wheel steel consists of pearlite, ferrite, ferrite fringes of $\sim 0.5-1.2 \mu \mathrm{m}$ thickness, size of cementite and ferrite plates in pearlite was $\sim 0.02-0.03 \mu \mathrm{m}$ and $\sim 0.07-0.1 \mu \mathrm{m}$, respectively. Size of subgrain of ferrite constituent rises on average in 1.3 times and makes $d_{\mathrm{s}} \sim$ $\sim 0.5-1.5 \mu \mathrm{m}$. Dislocation densityof $\mathrm{HAZ}$ in area I makes $\rho \sim(2-4) \cdot 10^{10} \mathrm{~cm}^{-2}$.

Thus, refining of substructure (in 2 times) at uniform 2-3 times increase of dislocation density takes place in the deposited metal from the side of wear surface at $\delta \sim 0-100 \mu \mathrm{m}$ distance from external surface. Such structural changes (dis-

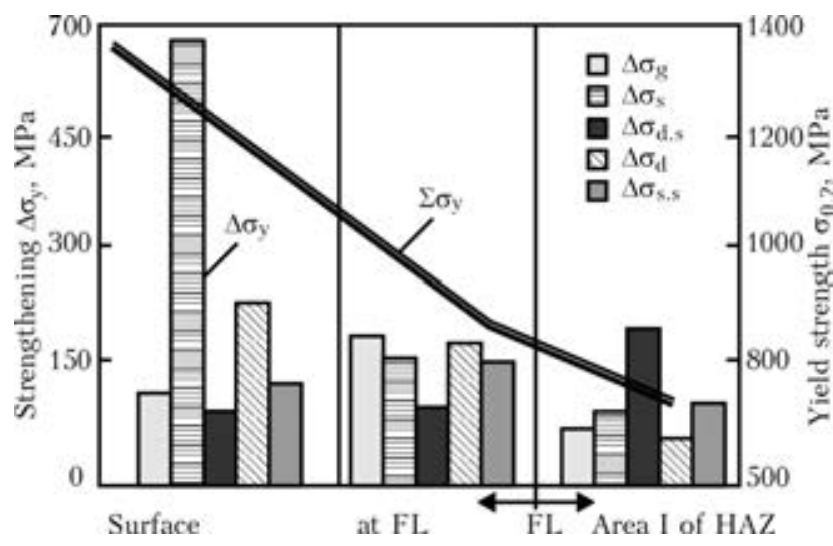

Figure 4. Diagrams reflecting input of grain $\Delta \sigma_{g}$, subgrain $\Delta \sigma_{\mathrm{s}}$, dispersed $\Delta \sigma_{\mathrm{d} . \mathrm{s}}$, dislocation $\Delta \sigma_{\mathrm{d}}$ and solid solution $\Delta \sigma_{\mathrm{s} . \mathrm{s}}$ strengthening in change of yield strength in deposited (PPAN180MN) metal and HAZ area I persion of structure at uniform distribution of dislocation density), obviously, should not promote for formation of local concentrators of internal stresses and reduction of metal crack resistance.

Comparison of strengthening effect of all structures forming in examined welds after service loading shows increase of general level of strength in surface layers of deposited metal. Dispersion of structure $\left(\Delta \sigma_{\mathrm{s}} \sim 682 \mathrm{MPa}\right)$ and uniform increase of dislocation density $\left(\Delta \sigma_{d} \sim 200-\right.$ $283 \mathrm{MPa}$ ) provide for increase of general level of strengthening on average by $60 \%\left(\Sigma \sigma_{0.2}=\right.$ $=1383 \mathrm{MPa}$ in comparison to weld metal, where $\Sigma \sigma_{0.2}=845 \mathrm{MPa}$ at $\delta \sim 0-200 \mu \mathrm{m}$ (PP-AN180MN, Figure 4). At that, values of $K_{1 c}$ in surface layers (at $\delta \sim 0-200 \mu \mathrm{m}$ ) of the deposited metal after service wear are approximately at one level. However, higher level of strength (by $16 \%$ higher in comparison to $\mathrm{Sv}-08 \mathrm{KhMF}$ ) is observed in the case of PP-AN180MN. It indicates good combination of mechanical characteristics of the deposited metal after wear.

Results of calculation estimations of local internal stresses $\tau_{1 . \text { in }}$ in comparison of their values with theoretical strength of material, given in

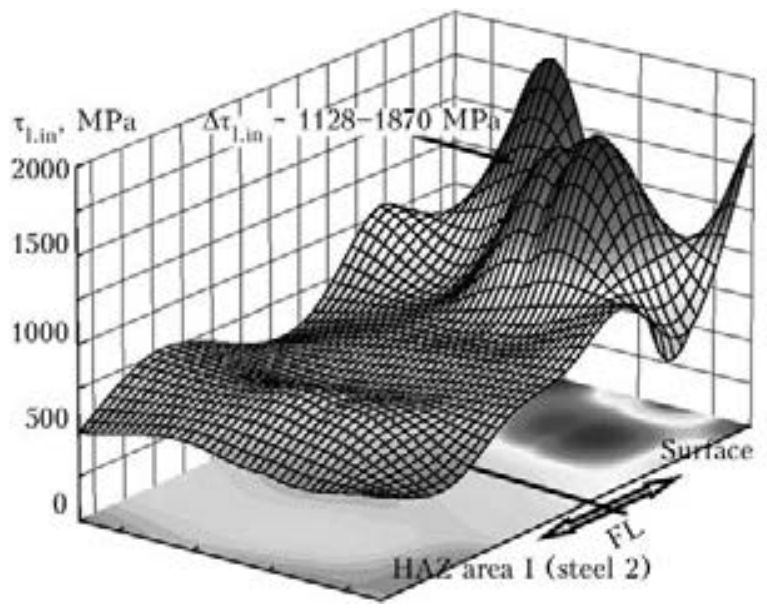

Figure 5. Level of local internal stresses forming in deposited (PP-AN180MN) metal after wear 
Figure 5, show the following. $\tau_{1 . \text { in }} \sim 740-$ $1100 \mathrm{MPa}$, making $(0.09-0.13) \tau_{\text {theor }}$, and uniformly distributed along weld metal are observed in the deposited metal. Level of forming internal stresses achieves $\tau_{\text {l.in }} \sim 1870 \mathrm{MPa}\left(0.22 \tau_{\text {theor }}\right)$ due to 2 times increase of dislocation density from $\rho \sim(4-6) \cdot 10^{10}$ up to $\rho \sim(1-2) \cdot 10^{11} \mathrm{~cm}^{-2}$ in approaching to external surface at $\delta \sim 0-200 \mu \mathrm{m}$ distance.

Thus, from point of view of strength indices, plasticity and crack resistance, the most optimum structure of deposited metal after wear is formed in PP-AN180MN application.

1. Pavlov, N.V., Kozubenko, I.D., Byzova, N.E. et al. (1993) Hardfacing of flanges of car wheel pair. $Z h$. D. Transport, 7, 37-40.

2. Sarzhevsky, V.A., Gajvoronsky, A.A., Gordonny, V.G. et al. (1996) Influence of technological factors on structure and properties of HAZ metal in repairrestoration hardfacing of flanges of car solid-rolled wheels. Avtomatich. Svarka, 3, 22-27, 33.
3. Gudkov, A.V., Lozinsky, V.N. (2008) New technological and technical solutions in field of railway transport welding. Vestnik VNIIZhT, 6, 3-9.

4. Markashova, L.I., Poznyakov, V.D., Gajvoronsky, A.A. et al. (2011) Evaluation of strength and crack resistance of railway wheel metal after long-term service. Fiz.-Khimichna Mekhanika Materialiv, 6, 73-79.

5. Goldshtejn, M.I., Litvinov, V.S., Bronfin, B.M. (1986) Physics of metals of high-strength alloys. Moscow: Metallurgiya.

6. Romaniv, O.N. (1979) Fracture toughness of structural steels. Moscow: Metallurgiya.

7. Gordienko, L.K. (1973) Ultrafine grain in metals. Moscow: Metallurgiya.

8. Gajvoronsky, A.A., Poznyakov, V.D., Markashova, L.I. et al. (2012) Influence of deposited metal composition on structure and mechanical properties of reconditioned railway wheels. The Paton Welding J., 8, 16-22.

9. Markashova, L.I., Poznyakov, V.D., Berdnikova, E.N. et al. (2014) Effect of structural factors on mechanical properties and crack resistance of welded joints of metals, alloys and composite materials. Ibid., 6/7, 22-28. 